\title{
TRIBUTAÇÃO IMOBILIÁRIA NO BRASIL. UM DIFÍCIL PERCURSO RUMO À POLÍTICA URBANA
}

\author{
Angela Penalva SAntos ${ }^{1}$
}

\begin{abstract}
Resumo - O artigo analisa o impasse da política urbana brasileira, dez anos depois das grandes expectativas trazidas pela entrada em vigor do Estatuto da Cidade (Lei 10.257/01). A tributação sobre a propriedade imobiliária foi um dos principais instrumentos jurídicos criados para controlar o processo de expansão urbana submetida ao princípio da função social da propriedade. $\mathrm{O}$ estudo da incorporação deste instrumento à normatividade de municípios selecionados mostrou que há ainda uma distância entre a previsão legal e a possibilidade efetiva do seu uso, o que levou a explorar algumas hipóteses explicativas do fenômeno.
\end{abstract}

Palavras-chave: Política urbana, tributação imobiliária, imposto predial e territorial urbano, estatuto da cidade, Brasil.

\begin{abstract}
PROPERTY TAXATION IN BRAZIL. A DIFFICULT PATH FOR URBAN POLICY. This article reviews the deadlock in Brazilian urban policy, ten years after the great expectations fueled by the enactment of the City Statute Law. Taxation of real estate was one of the principal legal tools created to control the process of urban expansion applied to the social involvement concerning property. The study of the incorporation of this tool into the normative processes of the municipalities shows that there is still some distance between the legal provision and the effective possibility of its use. Several hypotheses are proposed to explain this occurrence.
\end{abstract}

Keywords: Urban policy, real estate taxation, urban property tax, city statute, Brazil.

Résumé - IMPÔTS FONCIERS AU BRÉSIL. UN DIFFICILE PARCOURS VERS UNE POLITIQUE URBAINE. Cet article analyse la politique immobilière au Brésil, dix ans après le début du fonctionnement du Statut de la Ville (loi 10.257/01). La création d'un impôt sur la propriété immobilière a été l'un des instruments juridiques les plus efficaces pour contrôler le processus d'expansion urbaine et pour le soumettre au principe d'une fonction sociale de la propriété. Mais l'étude de quelques municipalités montre qu'il reste une appréciable

Recebido: Novembro 2012. Aceite: Junho 2013.

1 Economista, Doutora em Planejamento Urbano e Regional, Professora Associada da UERJ, pesquisadora do CNPQ. E-mail: angelapenalva@terra.com.br 
distance entre ce que la loi a prévu et la concrétisation effective de son usage. À ce sujet, quelques hypothèses d'explication sont proposées. Brésil.

Mots-clés: Politique urbaine, impôts fonciers, propriété urbaine, statut de la ville,

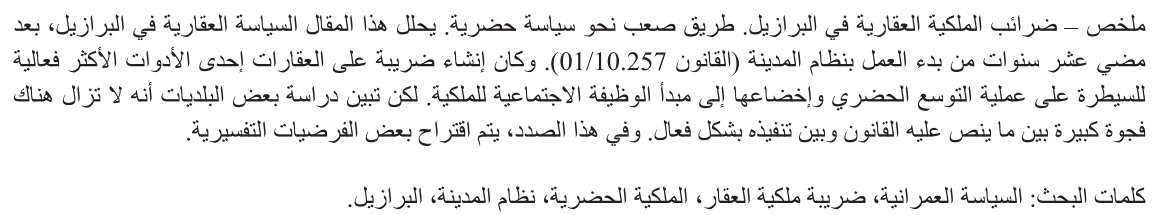

\section{INTRODUÇÃO}

Utilizar a tributação sobre a propriedade urbana foi uma das principais lutas do movimento pela reforma urbana ao longo da década de 1980. Depois de 21 anos de regime militar, a redemocratização das estruturas de poder incluiu a promulgação da Constituição de 1988, que elevou o município à condição de ente federativo e responsável pela política urbana. Desde então, o uso extrafiscal do Imposto Predial e Territorial Urbano (IPTU) foi um dos principais instrumentos de política urbana conforme se depreende da lei federal (Lei 10.257/2001) que regulamentou a política urbana, o Estatuto da Cidade.

O objetivo do estudo foi avaliar o uso da tributação imobiliária, em particular o IPTU, não apenas como instrumento arrecadatório, mas, principalmente, para fins de política urbana na primeira década do século XXI.

Além desta introdução há uma seção dedicada à análise geral da tributação imobiliária no Brasil apresentando inicialmente o peso da arrecadação dos tributos imobiliários em relação ao valor do PIB ao longo da década 2001/2010. Este foi o período posterior à entrada em vigor da lei federal que regulamentou os novos instrumentos jurídicos criados pela Constituição de 1988, criando expectativa de forte expansão da arrecadação tributária municipal.

A seguir analisa-se o uso do principal destes tributos, o Imposto Predial e Territorial Urbano (IPTU), como instrumento de política urbana, tomando por referência um estudo realizado num grupo de municípios localizados no Estado do Rio de Janeiro, marcados por fortes pressões demográficas - e, portanto, supostamente interessados em explorar melhor tais instrumentos.

$\mathrm{Na}$ terceira seção, discutem-se algumas hipóteses explicativas para o pouco sucesso do uso dos instrumentos tributários para a política urbana brasileira. Após 10 anos de vigência da Lei do Estatuto da Cidade, as cidades brasileiras não estão em melhor situação; pelo contrário, os municípios de médio e grande porte estão concentrando maior percentagem de população e a crise urbana está mais grave. Uma quarta e última seção é dedicada às conclusões. 


\section{A TRIBUTAÇÃO IMOBILIÁRIA NO BRASIL}

A expansão das cidades gera um forte impacto no mercado imobiliário, produzindo valorização da terra e suscitando maior controle público sobre a distribuição dos benefícios e dos custos envolvidos neste processo. Neste ambiente interagem dois pilares principiológicos da política urbana, que são a função social da propriedade e a função social da cidade.

O princípio da função social da propriedade caracteriza-se como limite e condição ao particular na fruição das faculdades inerentes ao seu direito de propriedade - usar, gozar, dispor e reaver da detenção injusta de terceiros (art. 1.228 do Código Civil). Dito de outro modo, a propriedade passa a sofrer uma série de condições para que esse direito individual se compatibilize com os interesses coletivos da realidade em que o bem está inserido. Conjugado ao referido princípio, tem-se a função social da cidade, que é a baliza do administrador público para definir que bens e direitos devem ser restringidos ou disponibilizados para atender ao interesse público. É com base no que se entende por função social da cidade que serão estabelecidos limites e condições ao direito de propriedade.

É no referido ambiente de intercâmbio entre o público e o privado que ingressa um terceiro princípio urbanístico, com o intuito de controlar o crescimento das cidades, que é a justa distribuição dos beneficios e ônus derivados do processo de urbanização (art. $2^{\circ}$, IX do Estatuto da Cidade). Ou seja, os melhoramentos ou restrições criados pelo Estado para promover a função social da cidade demandam a permanente gestão dos efeitos, positivos e negativos, ocasionados aos proprietários.

É neste contexto que a tributação sobre a propriedade imobiliária se tornou um instrumento de política urbana. Segundo o artigo 182 da Constituição do Brasil, o município é o ente federativo responsável por esta política. Visando cumprir essa competência constitucional, foram introduzidos vários instrumentos jurídicos regulamentados por lei federal (Estatuto da Cidade) que também devem ser regulamentados em esfera municipal de governo (quadro 1).

Quadro 1 - Tipos de tributação imobiliária no Brasil.

Table I - Types of property taxation in Brazil.

\begin{tabular}{lcc}
\hline \multirow{2}{*}{ Tributos sobre a propriedade imobiliária } & \multicolumn{2}{c}{ Competência } \\
\cline { 2 - 3 } & Municipal & Federal \\
\hline Imposto Predial e Territorial Urbano (IPTU) & $\mathrm{x}$ & \\
Imposto de Trasmissão de Bens Imóveis Inter Vivos (ITBI) & $\mathrm{x}$ & $\mathrm{x}$ \\
Imposto Territorial Rural (ITR) & & \\
Contribuição de Melhoria & $\mathrm{x}$ \\
\hline
\end{tabular}


Entre estes instrumentos, destacamos a tributação imobiliária, que abrange os seguintes tributos: Imposto Predial e Territorial Urbano (IPTU), Imposto de Transmissão de Bens Imóveis Inter Vivos (ITBI), Imposto Territorial Rural (ITR) e Contribuições de Melhorias, todos os tributos da esfera municipal de governo, exceto o ITR, cuja competência é federal. Portanto, o município é o responsável pela administração da maior parte dos tributos sobre a propriedade imobiliária, o que lhe confere grande poder pela utilização do instrumento tributário para fins de arrecadação fiscal e como indutor de usos da terra, de acordo com a sua função social (uso extrafiscal da tributação imobiliária).

Os tributos incidentes sobre a propriedade imobiliária não são os principais itens da arrecadação municipal, mas sim o Imposto sobre Serviços (ISS). Em 2010, as receitas de ISS somaram 30,4 bilhões de reais, o equivalente a $0,83 \%$ do PIB brasileiro e a $2,4 \%$ de toda a receita arrecadada no País. Trata-se de quase o dobro do que os municípios arrecadaram de IPTU, da ordem de 16 bilhões de reais, aproximadamente $0,4 \%$ do PIB (FINBRA/STN, 2010).

Além do IPTU, apenas o ITBI apresenta um desempenho arrecadatório relevante para as receitas municipais, totalizando 5,4 bilhões de reais em 2010, o que representa $0,14 \%$ do PIB, resultado que se deve ao aumento das transações imobiliárias e à elevação do preço dos imóveis. Os demais tributos imobiliários não têm relevância estatística para as finanças dos municípios brasileiros, contribuindo muito pouco para as suas receitas orçamentárias.

Um estudo de Carvalho Jr (2010) aponta o Brasil como um país que tributa pouco a propriedade imobiliária: algo como $0,4 \%$ do $\mathrm{PIB}$, percentagem bem inferior aos $0,8 \%$ cobrados em outros países de renda semelhante, como a África do Sul e a Argentina. Também é baixa a participação destes impostos na arrecadação local: aproximadamente $6 \%$, pouco quando se compara com os $25 \%$ na Nova Zelândia, França, Israel, e os 17\%. Na África do Sul.

Em relação à Portugal, o desempenho brasileiro é também pior. Em 2003, segundo o Public Finance Statistics do Fundo Monetário Internacional (FMI, 2003), a tributação sobre a propriedade imobiliária em Portugal correspondia a $0,62 \%$ do PIB, o equivalente a $1,46 \%$ das receitas governamentais do país e a $9,74 \%$ das receitas municipais. Destes valores, a maior parte corresponde a um tributo semelhante ao IPTU brasileiro, que soma $0,5 \%$ do PIB português, $(1,18 \%$ das receitas governamentais e $8,66 \%$ das receitas municipais).

Tal desempenho compromete não apenas o aspecto arrecadatório do imposto, mas também o papel extrafiscal que poderia desempenhar na política urbana. Citando Smolka e Schechinger (2005), Carvalho Jr observa que "países ou municípios que tenham uma tributação imobiliária ativa, conseguem regular de melhor forma o preço da terra, o acesso à habitação e prevenir melhor a informalidade que se traduz em favelas e outros assentamentos precários" (2010: 46).

Nesse estudo, Carvalho Jr considera que a baixa tributação efetiva no Brasil decorre menos da política de percentuais do tributo (alíquotas) e mais da ineficiência 
administrativa do aparelho fazendário. No Brasil, os tributos imobiliários pesam sobre a propriedade do bem, cujo valor é arbitrado pelo poder público. Em cidades que experimentam crescimento econômico, as Prefeituras enfrentam muitas dificuldades técnicas (para nem mencionar as dificuldades de ordem política) para atualizarem as plantas de valores imobiliários.

Tomando por referência o caso do município do Rio de Janeiro, verificamos que os percentuais do tributo são elevados, incidindo 1,2\% sobre o uso residencial, $2,8 \%$ para uso não-residencial e 3,5\% para terreno não-edificado. Entretanto, isso não compensa, na arrecadação, os descontos e a defasagem na avaliação imobiliária existente.

$\mathrm{Na}$ listagem das principais isenções e descontos do IPTU em municípios fluminenses a maior parte deles beneficia proprietários de imóveis pequenos (ainda que os "pequenos" variem de 40 a $70 \mathrm{~m}^{2}$ ); também aposentados são muito comumente beneficiados, assim como proprietários que tenham rendimento inferior a 3 salários mínimos.

No caso da capital fluminense, merece destaque um desconto de 3,6 mil reais no IPTU sobre terrenos não-edificados que, associado a outro de $40 \%$, incidente sobre Unidades Autônomas Populares (residências com valor venal inferior a cerca de 20 mil dólares, em 2010), além de outro desconto segundo uso do imóvel (variando entre os usos residencial, comercial e terreno) torna efetivamente $70 \%$ das unidades residenciais e 95\% das unidades territoriais isentas do IPTU (Carvalho, 2010).

Mais grave, contudo, é a desatualização das plantas gerais de valores (PGV). O Superior Tribunal de Justiça (STJ) decidiu que o reajuste destas plantas deve ser aprovado pelas Câmaras de Vereadores dos municípios. A dificuldade de a concretizar leva os executivos municipais a abdicarem dessa atualização, preferindo apenas reajustar os valores pelo índice de correção monetária, por meio de ato administrativo, sem ouvir o legislativo municipal.

\section{Desempenho fiscal dos tributos imobiliários}

Por todos estes motivos, a evolução da arrecadação do principal tributo sobre a propriedade imobiliária, o IPTU, apresentou um desempenho fraco, não acompanhando o crescimento do PIB brasileiro ao longo da primeira década do século XXI, como indicado no quadro II. Os municípios aumentaram a arrecadação própria, que passou de 1,29\% do PIB em 2001 para 1,66\% em 2010, mas este resultado deveu-se ao avanço do Imposto Sobre Serviços de Qualquer Natureza (ISS), especialmente nas grandes cidades, impactando positivamente na maior autonomia financeira local. Trata-se de imposto indireto, transferível para o preço final dos serviços, o que facilita o aumento do seu peso na arrecadação municipal, situação distinta da dos tributos diretos, como é o caso do IPTU. 
Quadro II - Evolução da arrecadação de impostos imobiliários nos municípios brasileiros, em percentagem do PIB, de 2001 a 2010.

Table II - Evolution of the real estate tax collections in Brazilian municipalities, as a percentage of GDP, 2001 to 2010.

\begin{tabular}{cccccc}
\hline & $\begin{array}{c}\text { Receita } \\
\text { tributária }\end{array}$ & IPTU & ITBI & ITR & $\begin{array}{c}\text { Contribuição de } \\
\text { Melhoria }\end{array}$ \\
\hline 2001 & 1,29 & 0,45 & 0,10 & 0,0072 & 0,0052 \\
2002 & 1,41 & 0,46 & 0,10 & 0,0363 & 0,0049 \\
2003 & 1,40 & 0,47 & 0,09 & 0,0111 & 0,0063 \\
2004 & 1,39 & 0,46 & 0,09 & 0,0075 & 0,0072 \\
2005 & 1,44 & 0,45 & 0,09 & 0,0064 & 0,0057 \\
2006 & 1,50 & 0,45 & 0,10 & 0,0065 & 0,0052 \\
2007 & 1,53 & 0,43 & 0,11 & 0,0068 & 0,0041 \\
2008 & 1,56 & 0,41 & 0,13 & 0,0062 & 0,0040 \\
2009 & 1,63 & 0,43 & 0,13 & 0,0100 & 0,0066 \\
2010 & 1,66 & 0,43 & 0,14 & 0,0118 & 0,0040 \\
\hline
\end{tabular}

Fonte: Elaborado a partir de dados da Secretaria do Tesouro Nacional - Finanças do Brasil, 2001/2010 e do IBGE, Sistema de Contas Nacionais, Referência 2000 (IBGE/SCN 2000 Anual), no sítio www.IPEADATA.gov.br

Quanto aos demais tributos imobiliários, o destaque é do ITBI, que evoluiu de $0,10 \%$ do PIB, em 2001 , para $0,14 \%$ no final da década. Há duas principais hipóteses explicativas para o melhor desempenho do ITBI frente ao IPTU. A primeira diz respeito a uma possível dinâmica do mercado imobiliário, o que de fato vem ocorrendo. Porém, a explicação mais provável é que sobre o ITBI não pesa a mesma dificuldade para atualizar a sua base de cálculo, como ocorre com o IPTU. Afinal, o ITBI é cobrado no ato da transmissão do bem imóvel e o seu pagamento é condição para registrar a nova propriedade no Registro Geral de Imóveis (RGI). Nestas condições, é grande o poder de "enforcement" do governo municipal, responsável por aceitar ou deliberar o valor venal do imóvel.

O ITR é um imposto de competência da União, apresentando uma baixa arrecadação, por ter menos uma função fiscal do que extrafiscal. Trata-se de um instrumento utilizado pela União na execução de sua política agrária, notadamente para combater os latifúndios improdutivos, que descumprem a função social da propriedade rural. Metade do valor arrecadado com este tributo é transferida para o município onde ocorreu o seu recolhimento. Em 2003, por meio da Emenda Constitucional 42, o município que se responsabilizar pela administração do tributo passa a ficar com a receita total da arrecadação. Essa é uma possibilidade que atrai mais os pequenos, com pouca ou nenhuma autonomia financeira, do que os grandes. O desempenho da arrecadação desta fonte de receita não é grande nem cresceu de forma significativa ao longo do período. Mas é provável que aumente a sua relevância à medida que os pequenos municípios vão aderindo à possibilidade de gerir o imposto, que é o que os dados da sua arrecadação nos anos 2009 e 2010 parecem sugerir. 
As Contribuições de Melhoria são ainda menos relevantes para as finanças municipais. As dificuldades para definir o alcance da valorização imobiliária decorrente de obra pública, assim como a limitação do seu valor (a ser dividido entre os proprietários afetados positivamente pela obra pública) ao montante despendido na referida obra, desestimula a cobrança pelos municípios de médio e grande porte. Já entre os pequenos, qualquer adicional arrecadado tem impacto no orçamento municipal e são esses os municípios responsáveis pela arrecadação das Contribuições de Melhoria, cobradas em obras de delimitação espacial facilmente definida, como é o caso de pavimentação de ruas.

A baixa tributação sobre a propriedade imobiliária no Brasil gera efeitos negativos sobre a autonomia municipal, comprometendo a capacidade de o município experimentar a descentralização da estrutura de poder permitida pela entrada em vigor da Constituição de 1988. Esse tem sido o resultado da transferência de responsabilidade para a esfera municipal da execução e parte do financiamento de políticas sociais como a Educação e Saúde. Se, por um lado, representa o fortalecimento institucional do município, por outro, gera aumento do comprometimento das finanças municipais com estas políticas. Há estudos que analisam a (in)capacidade de financiamento dos governos municipais frente aos compromissos que assumiram na execução de políticas públicas, como os de Santos (2008), e o de Garson (2009), mas a consequência mais grave é a não-utilização dos instrumentos tributários para fins de política urbana, conforme expectativa criada com o Estatuto da Cidade, em 2001.

\section{O uso do IPTU como instrumento de política urbana}

O IPTU é um instrumento que deveria estar sendo explorado pelos municípios para controlar o processo de expansão urbana, submetendo a propriedade urbana à sua função social. De facto ele é o principal tributo incidente sobre a propriedade imobiliária, da competência do município, o ente federativo que também é responsável pela política urbana. Além de instrumento de arrecadação, este imposto tem grande importância no processo de valorização imobiliária que resulta da dinâmica urbana, podendo ser utilizado para redistribuir a renda urbana.

O arbitramento dos valores deste tributo deve levar em consideração a disponibilidade de bens e serviços públicos no local onde está situado o imóvel, os fins para os quais ele é destinado e o valor de mercado do imóvel. Para tal desígnio, o município deve realizar um tratamento qualitativo dos imóveis e isso é possível através da fixação de percentuais do tributo (alíquotas), diferenciados pelo uso e localização do imóvel, servindo ainda para induzir usos adequados da terra, em linha com o Plano Diretor Municipal.

Desde a promulgação da Emenda Constitucional no 29/2000, o município pode estabelecer distintas modalidades de cobrança do IPTU, podendo instituir alíquotas: a) progressivas por base de cálculo; b) diferenciadas por localização dos imóveis; 
c) qualificadas por espécie de uso existente no bem; e d) progressiva no tempo em função da não edificação, não utilização ou subutilização do imóvel. Tais modalidades referem-se ao uso extrafiscal do tributo para fins de política urbana.

Este instrumento tributário tende a ser maior entre os municípios de grande porte demográfico, dotados de melhor capacidade técnica de seus funcionários, como deveria ser o caso dos municípios fluminenses, situados no Estado do Rio de Janeiro. Trata-se da segunda maior economia estadual, com participação de aproximadamente $12 \%$ do PIB brasileiro. Sua capital, a cidade do Rio de Janeiro, foi capital do País por quase 200 anos (de 1763 a 1960) e é a segunda maior cidade em população, contando com 6,3 milhões de habitantes.

Pesquisa realizada entre 11 municípios fluminenses buscou avaliar o uso do IPTU como instrumento de política urbana (Santos e Luft, 2012). A escolha dos municípios restringiu-se aos que tinham população superior a 100 mil habitantes, incluindo a capital estadual e os três principais situados na região metropolitana (São Gonçalo, Duque de Caxias e Nova Iguaçu), todos com população de aproximadamente 1 milhão de habitantes. Além destes, foram incluídos os sete municípios que experimentaram maior crescimento demográfico na primeira década do século XXI (Angra dos Reis, Araruama, Cabo Frio, Itaboraí, Macaé, Maricá e Rio das Ostras). Estes foram considerados, em tese, os municípios mais interessados em utilizar o instrumento tributário para ordenar a expansão urbana. As fontes de investigação abrangeram a legislação local, sobretudo leis orgânicas, planos diretores e códigos tributários municipais.

Os resultados encontrados no que tange ao uso de percentuais diferenciados do tributo (alíquotas) foram os seguintes: a) os 11 municípios têm alíquotas diferenciadas segundo o imóvel seja edificado ou não, e todos prevêem o IPTU progressivo no tempo para imóveis não edificados; b) 5 entre os 11 municípios prevêem alíquotas diferenciadas por base de cálculo do valor do imóvel; c) apenas 3 diferenciam alíquotas pelo fator localização do imóvel; d) 6 entre os 11 municípios contam com alíquotas diferenciadas por uso do imóvel (residencial ou comercial/industrial). Quando a pesquisa analisou a regulamentação do IPTU progressivo e as isenções deste imposto, os resultados encontrados foram: a) 5 municípios regulamentaram as áreas de incidência do dito imposto; b) apenas 4 regulamentaram as alíquotas progressivas; c) isenções do tributo estão previstas para atividades ambientais e culturais em 9 dos 11 municípios; d) em apenas 4 municípios estão previstas isenções para uso residencial em habitação social.

Nenhum dos 11 municípios está em condições legais plenas de aplicar o IPTU progressivo no tempo, ainda que a maioria tenha introduzido em sua legislação a possibilidade de utilização deste instrumento de política urbana. Nem mesmo observamos o uso do recurso a isenções do imposto associado à política habitacional de interesse social. $\mathrm{O}$ resultado sugere que os municípios não querem fazer uso, ou desconhecem, o arsenal jurídico a sua disposição.

Este resultado está em linha com a pesquisa denominada "Os Planos Diretores Municipais Pós-Estatuto da Cidade. Balanço crítico e perspectivas" (Santos Jr e 
Montandon, 2011). Neste estudo, os autores relatam os parcos resultados frente à grandiosidade das expectativas alimentadas com a normatividade urbanística, comprometida com os princípios do Estatuto da Cidade. As elevadas expectativas referem-se à luta empreendida pelo Movimento Nacional pela Reforma Urbana ao longo das décadas de 1970 e 1980, que logrou introduzir importantes avanços normativos no ordenamento urbanístico na Constituição de 1988 (Maricato, 2011).

\section{A TRIBUTAÇÃO IMOBILIÁRIA ESTARÁ A SER USADA COMO INSTRUMENTO DE POLÍTICA URBANA?}

A arrecadação dos tributos imobiliários não acompanhou a evolução do PIB brasileiro ao longo da primeira década do século XXI, ainda que tenha sido encontrada evidência de que houve aumento desta arrecadação (Santos, 2008; Carvalho Jr, 2010). Mais grave, entretanto, foi o pior resultado encontrado em relação à utilização do seu principal tributo para fins de política urbana. A análise da legislação relativa ao IPTU como instrumento de política urbana indicou que há grande distância entre as oportunidades do uso extrafiscal do tributo em relação às práticas em curso.

Cabe lembrar, no entanto, que as ações de planejamento urbano não se restringem à regulação do uso do solo (o que é tratado por meio da legislação urbanística), mas inclui o fomento ao desenvolvimento urbano, tornando necessário que sejam analisadas questões relativas ao seu financiamento (o que não é tratado pelo Estatuto da Cidade).

Nas seções a seguir, analiso alguns aspectos relacionados à dinâmica econômica e ao contexto federativo em que se insere o município na estrutura federativa brasileira visando explicar a pouca efetividade na utilização da tributação sobre a propriedade imobiliária como instrumento de política urbana.

\section{Aspectos econômicos}

Ao longo do século XX, o Brasil experimentou intenso processo de urbanização, com população muito concentrada em municípios de médio e grande porte. A forte polarização espacial da população, em um número reduzido de grandes municípios, levou ao acirramento da crise urbana, alimentando movimentos sociais em favor da reforma urbana. Esta luta esteve mais identificada com a crise das metrópoles que haviam crescido devido ao processo de industrialização, cujo auge ocorreu entre as décadas de 1930 e 1970.

Nestas condições, o movimento pela reforma urbana desenvolveu uma abordagem crítica dessa industrialização, identificando o planejamento urbano dos anos 1960 e 1970 como uma resposta à necessidade de ordenar o território com vista às demandas do processo de industrialização (Monte-Mór, 2005). 
Entretanto, tal planejamento urbano não atentou para duas áreas que se tornariam críticas na dinâmica das nossas cidades: a moradia popular e a mobilidade urbana. Superar essa deficiência foi o principal objetivo da luta pela reforma urbana, o que levou à mudança do foco das ações do planejamento para o acesso à terra urbana, considerado o "nó" do processo de crescimento das cidades. Emergiu assim uma nova interpretação sobre o fenômeno da disseminação do processo de expansão urbana.

A avassaladora urbanização mundial gerou imensas áreas urbanas que têm empurrado os pobres para as franjas desses espaços, onde o preço da terra é mais baixo e, assim, acessível à população de menor nível de renda. O menor preço, no entanto, é a expressão da inadequação da infraestrutura, o que representa um custo para o deslocamento quotidiano da população que ali reside.

Durante a fase em que o setor industrial comandou a dinâmica econômica, havia tendência para a aglomeração espacial e a geração de metrópoles; estas articulavam o território dos Estados Nacionais em benefício do processo de industrialização, tornando as demais cidades ou regiões dependentes das decisões emanadas desde aquele núcleo industrial e demográfico líder. Depois do último quartel do século XX, contudo, a indústria vem perdendo centralidade na dinâmica econômica e as metrópoles perderam atratividade como lócus da indústria, tornando-se "economias de serviços", mas continuam sustentando a polarização espacial.

Esta maior concentração está associada à criação de oportunidades de trabalho, como sugere a análise da distribuição espacial dos empregos formais gerados no país ao longo da primeira década do século XXI. Conforme identificado por Santos (2012a), são as cidades de maior porte populacional, aquelas onde está concentrada a maior parcela de todos os empregos formais, que estão protegidos por legislação trabalhista, as que proporcionam maior segurança aos trabalhadores. Apesar de ser pequeno o número de municípios (283, correspondente a $5,1 \%$ do total), com população superior a 100 mil habitantes, eles participam com elevada percentagem da população $(54,75 \%)$ e da criação de empregos $(75,96 \%)$ do país, o que os leva a experimentarem fortes pressões demográficas, que seguem gerando os já conhecidos efeitos da crise urbana vivenciada pelas metrópoles.

A evidência da força econômica deste grupo de cidades médias e grandes sugere que, sob o atual paradigma econômico, a crise urbana tende a estar identificada com a crise das metrópoles e de um grupo de cidades médias, que cumprem o papel de articuladoras do território em escala regional. São essas as cidades que enfrentam o desafio de ordenar o crescimento sem alimentar a crise urbana. Mas, sob o forte dinamismo que a maior geração de empregos nestas localidades apresenta, as prefeituras têm deixado de utilizar os instrumentos jurídicos criados para controlar a apropriação privada de rendas fundiárias, lançando mão de outros instrumentos, em particular aqueles que incluem as chamadas parcerias público-privadas.

O caso das "operações urbanas consorciadas" é paradigmático. Na cidade do Rio de Janeiro, só em fevereiro de 2011 houve a edição do Plano Diretor (Lei Complementar 111/2011) compatível com as inovações introduzidas pelo Estatuto da 
Cidade (Lei 10.257/2001). Antes disso, porém, o governo municipal decidiu realizar obras de revitalização da área portuária, motivo da criação da Companhia de Desenvolvimento Urbano da Região do Porto do Rio (CDURP) regulada pela Lei Complementar 102/2009. Para realizar as obras, houve a edição anterior de outra lei (Lei Complementar 101/2009) regulamentando as "operações urbanas consorciadas", instrumento previsto pelo Estatuto da Cidade (art. 32) desde 2001. Vale dizer que, antes de regulamentar todos os instrumentos do Estatuto da Cidade, a prefeitura carioca regulamentou apenas os instrumentos que lhe permitiram adiantar recursos para financiar investimentos em infraestrutura urbana, por meio de parceria com a iniciativa privada.

\section{Aspectos federativos}

Um elemento muito importante que deve ser considerado nas análises sobre as limitações desta normatividade para a política urbana é o papel do município no federalismo brasileiro. A legislação do Estatuto da Cidade tomou como princípio o fortalecimento institucional dos municípios, que foram considerados responsáveis pela política urbana, conforme definido no artigo 182 da Constituição Brasileira. Ademais, os municípios receberam maiores responsabilidades pela execução de políticas públicas sociais, de responsabilidade compartilhada entre as três esferas de governo - as chamadas competências legislativas concorrentes e competências materiais comuns. A autonomia política conquistada pela elevação de sua condição a "ente federativo" alimentou expectativas exageradas quanto à sua capacidade de controlar o processo de expansão urbana.

Houve forte crítica a respeito de tal fortalecimento municipal sob o argumento de que a excessiva fragmentação territorial comprometeria a capacidade do poder público planejar e ordenar o território (Brandão, 2007). Mas a Constituição também introduziu artigos definindo os governos estaduais como responsáveis pelo ordenamento do território em escala regional, ficando o governo federal responsável pelo ordenamento do território em escala nacional (Santos, 2010). Não houve, contudo, planejamento em escala regional nem nacional até a criação do Ministério das Cidadesii, em 2003. Neste ínterim (1988-2003) prevalecia o entendimento de que cabia às prefeituras ordenar o território, ainda que muitas políticas setoriais, sobretudo a do saneamento ambiental, não sejam passíveis de estarem circunscritas à escala municipal.

Após a criação do Ministério das Cidades, o governo federal buscou superar o problema das escalas, por meio do estímulo ao que ficou conhecido como "coordenação federativa". Trata-se de uma estratégia segundo a qual o governo federal formula o desenho institucional da política e estimula a adesão dos estados e municípios, por meio da oferta de recursos que contribuem (total ou parcialmente) para o financiamento das ações governamentais.

Assim, a partir do Governo Lula (2003/10), a autonomia municipal seria respeitada, mas os municípios receberam estímulos financeiros para participar de pactos 
federativos para execução dos serviços inerentes a várias políticas setoriais, o que inclui o já mencionado setor de Saneamento, mas também serviços de Saúde e Educação, além de Moradia Social. O consorciamento municipal passou a ser estimulado, bem como a formação de redes federativas verticais e, sobretudo, aumentou o peso das "transferências de capital" nas receitas orçamentárias dos municípios ${ }^{\mathrm{iii}}$ (Santos, 2012b). Conforme dados da Secretaria do Tesouro Nacional, entre 1995 e 2010 , o peso desta fonte nas receitas municipais foi elevado de $1,77 \%$ para $3,18 \%$. Esta elevação não foi gradual, mas cresceu ao longo dos mandatos dos Presidentes Fernando Henrique Cardoso (1995/2002) e Lula da Silva (2003/2010), sugerindo a sua utilização política como instrumento de troca entre os interesses do Poder Executivo (responsável pela elaboração do orçamento) e o Poder Legislativo (a quem compete emendar e aprovar a proposta orçamentária).

Esta coordenação federativa correspondeu a um fortalecimento do governo federal, a uma renovação do tradicional centralismo das políticas públicas, ainda que pactuado entre entes federativos. Tal coordenação vem permitindo mitigar a alegada fragmentação territorial, mas também implica a diminuição dos espaços para o surgimento de inovações na área da gestão das políticas públicas nos municípios, como ocorreu na década de 1980.

Aquelas inovações (que incluíram a utilização do orçamento participativo e as políticas de transferências condicionadas de renda, como o Programa Bolsa Escola, origem do atual programa federal Bolsa Família) foram introduzidas por governos municipais eleitos com o apoio dos movimentos sociais. $\mathrm{O}$ ímpeto reformista das lideranças destes movimentos seria arrefecido com a chegada ao poder, do Presidente Lula, ocorrendo mesmo a sua cooptação pelo governo federal (Maricato, 2011).

À fraca autonomia municipal correspondeu, assim, a crescente dependência financeira do governo federal, ainda que não tenha havido perda de autonomia política. $\mathrm{O}$ resultado tem sido a prevalência das prioridades do governo federal sobre os controles urbano-ambientais introduzidos pelo Estatuto da Cidade. A prioridade do governo federal ao longo da última década tem sido sustentar o crescimento econômico, gerador de mais empregos, permitindo a ascensão de aproximadamente 30 milhões de brasileiros pobres à condição de consumidores de uma nova classe média, com rendimentos entre 3 e 10 salários mínimos (Neri, 2010).

Ao observar o impacto do crescimento econômico no território, verifica-se que houve alguma redistribuição macrorregional a favor das regiões Centro Oeste e Nordeste, o que deve ser comemorado. No entanto, um olhar intra-regional revela-nos que o crescimento está concentrado nas cidades de médio e, sobretudo, grande porte, as capitais estaduais, em primeiro lugar.

\section{Avanços normativos em xeque}

Conforme já mencionado, o impacto concentrado da geração de empregos nestas cidades sugere que a prioridade do governo federal está alimentando a crise urbana das metrópoles nacionais e regionais. Este resultado, longe de suscitar maior 
preocupação das prefeituras, é comemorado pelo efeito positivo que causa no aumento do emprego, da renda e da arrecadação fiscal. Neste cenário, os prefeitos dão pouca prioridade ao controle do crescimento urbano e, portanto, fazem menor uso dos instrumentos tributários introduzidos pelo Estatuto da Cidade.

Urbanista identificada com o movimento pela reforma urbana, que lutou pela criação do Ministério das Cidades, e sua primeira Secretária Executiva, Ermínia Maricato (2011) buscou entender o pouco sucesso do avanço normativo do Estatuto da Cidade em gerar cidades mais inclusivas, mais justas. Mas concedeu grande responsabilidade ao ajuste neoliberal realizado no Brasil durante a década de 1990. No entanto, na década seguinte, a crise urbana tornou-se mais aguda, como ela própria reconheceu, ainda que sob um governo comprometido com os movimentos sociais, do Presidente Lula, marcado pela retomada do crescimento da economia brasileira e pela expansão dos gastos públicos. Sem priorizar ajuste fiscal, portanto.

Nunca é demais lembrar que as intervenções no espaço urbano experimentadas no passado não seriam possíveis se estivessem submetidas a legislação urbanística atual. Os desmontes dos morros do Castelo (década de 1920) e Santo Antônio (década de 1950) no centro da cidade do Rio de Janeiro não poderiam ser aprovadas no presente marco regulatório urbanístico. Mesmo intervenções mais recentes, na década de 1970, que incluíram a demolição de patrimônio histórico para obras do metrô, não seriam realizadas a partir dos anos 1990. Outro exemplo que merece ser destacado refere-se ao atraso e reformulação do projeto de instalação de um complexo petroquímico em Itaboraí (município localizado na Região Metropolitana do Rio de Janeiro) devido à legislação urbano-ambiental, preocupação que inexistia por ocasião da implantação de antigos polos petroquímicos que, a exemplo de Paulínia (no Estado de São Paulo) causou graves índices de poluição.

Cabe reconhecer, entretanto, que sob a atual dinâmica econômica, a polarização espacial vem-se intensificando e tornando as cidades polos que seguem atraindo capitais e população. Nestas condições, a terra urbana tornou-se uma fronteira para a aplicação de grande rentabilidade pelo capital imobiliário. Diante destas oportunidades rentáveis, os interesses empresariais enfrentam facilmente os custos adicionais gerados pela legislação urbanística. Assim, a crise urbana vai-se reproduzindo e mostrando os limites dos instrumentos jurídicos em controlar e orientar a expansão destas cidades, o que gera enorme frustração aos urbanistas que lutaram pela reforma urbana.

\section{CONCLUSÕES}

O que dizer, então, das perspectivas do uso da tributação imobiliária como instrumento de política urbana? Reconhecer seus limites não significa desconsiderar sua relevância. $\mathrm{O}$ avanço da legislação urbanística tem representado limitações ao uso mercantilizado da terra urbana em prol do interesse coletivo, expresso na função social da propriedade e da cidade. 
Os avanços normativos experimentados no Brasil fazem parte de uma abordagem de política urbana que acompanha a agenda do direito à cidade difundida pela Agência Habitat/ONU. O entendimento do que seja o "direito à cidade" passou a incluir acesso a direitos sociais recepcionados na Constituição, como nos casos da Educação, Saúde, Assistência Social e também a Moradia. Esta última ganharia um sentido de "moradia adequada", denominação para uma edificação regularizada em termos fundiários e acessível à rede de infraestrutura necessária à vida cotidiana, caso das redes de energia, transportes e saneamento.

Nesse contexto duas visões passam a disputar o sentido do planejamento urbano, produzindo distintas agendas de política urbana: a abordagem da urbanização social e o empreendedorismo urbano. A primeira está identificada com a agenda dos direitos, um dos quais o direito à cidade. Mas é a segunda que vem predominando na administração das cidades, em particular nas metrópoles, como é o caso atual da cidade do Rio de Janeiro, que vem sofrendo intenso processo de transformação espacial sustentado no projeto de sediar os Jogos Olímpicos de 2016.

E, no entanto, cada um ilumina uma parte da questão urbana. O urbanismo social remete para a necessidade de administrar a cidade de modo a torna-la acessível a sua população, permitindo-lhe o acesso à terra e à infraestrutura urbana. Já o planejamento por projeto facilita mobilizar recursos em escala suficiente para implementar grandes blocos de investimentos, que demandam complexa engenharia financeira.

Cabe ainda lembrar que o planejamento urbano também envolve dimensões distintas que precisam ser consideradas: a regulação do uso do solo e o fomento ao desenvolvimento urbano.

A regulação do solo é representada pela legislação urbanística visando o controle do processo de expansão urbana, em prol do direito a cidades social e ambientalmente sustentáveis. Trata-se de uma dimensão de direito "em negativo", impedindo usos incompatíveis e em favor da manutenção do interesse coletivo.

Já o fomento ao desenvolvimento urbano envolve "prestações positivas" do Estado, isto é, alocação de recursos orçamentários para financiar a expansão da infraestrutura. Num contexto de crescimento extensivo da mancha urbana, extravasando para outros municípios e formando metrópoles muito mais complexas do que as cidades nucleares, torna-se necessária a intervenção pública para viabilizar a produção de bens públicos, como são os casos da malha viária e da rede de saneamento. Tais investimentos pesados, por sua vez, tendem a produzir vetores de expansão urbana suscitando respostas do mercado imobiliário que geram mais demandas por infraestrutura urbanística. O resultado tende a envolver mais "engenharia financeira" para administrar cidades cujos compromissos não são simples gestão local, mas sim parcelas significativas da economia do País.

Neste contexto, a tributação imobiliária deve fazer parte da agenda dos governos municipais, porque contribui para as duas faces dos desafios que as grandes cidades enfrentam: tanto podem ser utilizadas como instrumento para regular o uso do solo, como para aumentar a arrecadação fiscal, viabilizando o financiamento da 
infraestrutura urbanística. Cabe, assim, lutar para dar efetividade a esse instrumento de tão grande potencial para melhorar a administração pública nas cidades, cuidando simultaneamente do ordenamento urbanístico com mais justiça na distribuição dos benefícios e ônus derivados do processo de urbanização (art. 2, IX do Estatuto da Cidade).

\section{AGRADECIMENTOS}

Este artigo é parte do projeto "Política Urbana no Contexto Federativo Brasileiro" que tem sido apoiado pela Bolsa de Produtividade em Pesquisa PROCIÊNCIA/UERJ e do CNPQ/Ministério de Ciência e Tecnologia do Brasil.

Agradeço ao bolsista de Iniciação Científica/CNPQ, aluno do curso de Ciências Econômicas/ UERJ, Arthur Pitanga, pelo levantamento e organização dos dados secundários.

Finalmente, agradeço aos avaliadores da revista Finisterra por suas pertinentes críticas que muito me ajudaram a melhorar o presente artigo. Erros e omissões que eventualmente tenham persistido são de minha inteira responsabilidade.

\section{BIBLIOGRAFIA}

Brandão C A (2007) Território \& desenvolvimento. As múltiplas escalas entre o local e o global. Editora da UNICAMP, Campinas.

Carvalho Jr P H (2010) O sistema avaliatório municipal de imóveis e a tributação do IPTU no Rio de Janeiro. Dissertação de Mestrado em Economia/ UERJ.

FINBRA/Secretaria do Tesouro Nacional (2010) Finanças do Brasil, 2001/2010. Acedido a 18/11/2011 [www.stn.gov.br].

FMI (Fundo Monetário Internacional) (2003) Supplement to the 2002 Government Finance Statistics Yearbook, January 2003. Public Finance Statistics. Acedido a 10/01/2012 [www.imf.org].

IBGE - Sistema de Contas Nacionais, Referência 2000 (IBGE/SCN 2000 Anual). Acedido a 18/11/2011 [www.ipeadata.gov]

Maricato E (2011) O impasse da política urbana no Brasil. Petrópolis: Vozes.

Monte-Mór R (2005) A questão urbana e o planejamento urbano-regional no Brasil. In Diniz C, Lemos M (org.) Economia e território. Editora da UFMG, Belo Horizonte: 429-446.

Neri M (coord.) (2010) A pequena grande década. Crise, cenários e a nova classe média. Centro de Políticas Sociais da Fundação Getúlio Vargas, São Paulo.
Santos A M S P (2012a) Cidades médias: novas fronteiras de oportunidade. In Santos A, Marafon G, Sant'Anna M (coord) Rio de Janeiro: um território em mutação. Gramma, Rio de Janeiro: 47-72.

Santos A M S P (2012b) Finanças Públicas: uma análise da autonomia financeira dos municípios brasileiros na primeira década do século XXI. SINTESE - Revista da Escola de Contas e Gestão do Tribunal de Contas do Estado do Rio de Janeiro, 7(1): 26-42.

Santos A M S P (2010) Os desafios da política urbana: o que sugere a experiência de Macaé e Rio das Ostras? In Santos A, Marafon G, Sant'Anna M (coord) Rio de Janeiro: um olhar sociespacial. Gramma, Rio de Janeiro: 101-129.

Santos A M S P (2008) Município, descentralização e território. Forense, Rio de Janeiro.

Santos A M S P, Luft R M (2012) Tributação imobiliária e política urbana no Brasil. In Santos A, Marafon G, Sant`Anna M (coord) Rio de Janeiro: um território em mutação. Gramma, Rio de Janeiro: 251-279.

Santos Jr O A, Montandon D T (org.) (2011) Os Planos Diretores Municipais Pós-Estatuto da Cidade: balanço crítico e perspectivas. Letra Capital, Rio de Janeiro. 
i No Brasil existem três elementos federativos: a União, os Estados e os Municípios.

ii As políticas públicas urbanas foram reunidas num mesmo órgão fortalecido institucionalmente pela elevação à condição de ministério, o mais alto grau de órgão público da administração pública federal.

iii Tratam-se de receitas de transferências não-obrigatórias; não representam um fluxo de receitas regulares, mas sim um estoque de financiamento a ser executado num período só, válido dentro de uma lei orçamentária anual. No Brasil, estas transferências são introduzidas no orçamento federal por meio de emendas de parlamentares ao orçamento enviado pelo poder executivo para aprovação, após emendas, pelo poder legislativo. 